\title{
KESABARAN DAN ACADEMIC SELF-EFFICACY PADA MAHASISWA
}

\author{
Rizka Fitri Nugraheni \\ Fakultas Psikologi Universitas Indonesia Jakarta \\ Email: rizka_fn@yahoo.com
}

\begin{abstract}
The aim of this research was to find whether there's relationship between academic self-efficacy and shabr, as well as its supporting aspects. Participants were 108 undergraduate students. The instruments used were adapted version of College Questionnaire Academic Self-efficacy (Owen \& Froman, 1988) and Shabr questionnaire (El Hafi, Rozi, \& Mundzir, 2013). Data were analyzed with Pearson correlation. Results showed that there's significant correlation between shabr and academic self-efficacy. This finding can contribute to shabr theory construction and enhance comprehensive understanding about shabr among the community.
\end{abstract}

Keywords: Academic self-efficacy, shabr, student

\section{INTISARI}

Penelitian ini berusaha mencari tahu apakah terdapat hubungan antara academic self-efficacy dan sabar beserta aspek-aspek pendukungnya. Subjek adalah 108 mahasiswa. Instrumen penelitian meliputi College Questionnaire Academic Self-efficacy (Owen \& Froman, 1988) yang diadaptasi dan kuesioner kesabaran (El Hafi, Rozi, \& Mundzir, 2013). Data diolah dengan teknik korelasi Pearson. Hasil analisis statistik menyatakan bahwa terdapat korelasi yang signifikan antara kesabaran dan academic selfefficacy. Temuan ini dapat berkontribusi terhadap konstruksi teori sabar dan memberikan pemahaman yang komprehensif pada masyarakat mengenai makna sabar.

Kata kunci: Academic self-efficacy, sabar, mahasiswa

M[ ahasiswa pada umumnya mempunyai target dan menghadapi tantangan akademis. Mereka memerlukan keyakinan bahwa dirinya mampu melakukan hal-hal yang diperlukan hingga target tercapai dan tantangan dapat dihadapi. Dengan kata lain, mereka membutuhkan self-efficacy yang baik. Self-efficacy didefinisikan oleh Bandura (1986) sebagai penilaian terhadap kemampuan diri sendiri dalam menjalankan rangkaian perilaku untuk mencapai suatu tujuan. Self-efficacy dapat mempengaruhi pilihan perilaku, besar usaha yang dikeluarkan dan seberapa lama bertahan ketika mengalami hal yang tidak menyenangkan, pola pikiran, dan reaksi emosi. Orang dengan self-efficacy yang tinggi cenderung memilih kegiatan menantang, terus berusaha keras dan tetap bertahan dalam usahanya walaupun mengalami hal tidak menyenangkan. Perilaku tersebut terpolakan dalam pikiran dan tercerminkan dalam reaksi emosinya. Konsep self-efficacy juga berlaku dalam konteks akademis sehingga dapat disebut juga sebagai academic self-efficacy. Beberapa penelitian yang dipaparkan dalam Zimmerman (2000) mendukung pernyataan Bandura (1986), yaitu academic self-efficacy dapat memprediksi pilihan aktivitas, tingkat usaha, seberapa lama bertahan dalam usahanya, dan reaksi emosi. 
Konsep self-efficacy bersifat spesifik terhadap bidang yang berkaitan dengan target perilaku, contohnya, self-efficacy seseorang bisa tinggi dalam olahraga namun rendah dalam fisika. Self-efficacy juga dapat berbeda antar individu walaupun dalam satu bidang. Salah satu faktor penyebab perbedaan itu adalah jenis kelamin. Berdasarkan temuan Lindstrøm dan Sharma (2011), perempuan cenderung memiliki selfefficacy yang lebih rendah daripada laki-laki dalam mempelajari fisika. Temuan lain oleh Williams dan Takaku (2011) mengungkapkan hal yang berbeda, bahwa tidak ada perbedaan antara laki-laki dan perempuan dalam writing self-efficacy.

Temuan-temuan terkini mengungkapkan pengaruh academic self-efficacy terhadap aktivitas akademis mahasiswa. Salah satunya adalah pencapaian target akademis yang dapat diukur dengan Indeks Prestasi Kumulatif (IPK). Penelitian Feldman dan Kubota (2015) mengungkapkan bahwa IPK dapat diprediksi oleh academic self-efficacy. Artinya, individu yang yakin mampu melakukan berbagai hal dalam rangka mencapai target IPK, cenderung mendapatkan IPK yang ditargetkan. Pengaruh academic self-efficacy pada IPK juga dapat dimediasi oleh faktor lain, yaitu effort atau usaha untuk mencapai target (Li, 2012).

Usaha dapat berupa self-regulation dalam belajar. Mahasiswa dengan selfefficacy yang tinggi mengatur dirinya dalam belajar dan cenderung tidak melakukan prokrastinasi (Klassen, Krawchuk, \& Rajan, 2008). Perilaku tersebut mengindikasikan adanya usaha yang tekun pada mereka. Ketekunan juga disertai dengan kegigihan dalam berusaha, sebagaimana temuan
Komarraju dan Nadler (2013), yaitu mahasiswa dengan self-efficacy yang tinggi dapat berusaha secara terus-menerus untuk mencapai target walaupun menghadapi kesulitan.

Hasil penelitian Komarraju dan Nadler (2013) menunjukkan bahwa academic selfefficacy yang tinggi diperlukan mahasiswa dalam menghadapi kesulitan yang dapat berasal dari keadaan lingkungan akademis. Situasi lingkungan akademis seperti dosen, prasarana, dan materi kuliah, akan dipersepsikan oleh mahasiswa sebagai sesuatu yang nyaman atau sebaliknya. Faktor persepsi terhadap lingkungan akademis dapat berpengaruh pada prestasi mahasiswa, namun pengaruh tersebut akan lebih kuat jika mahasiswa memiliki academic selfefficacy yang baik (Abd-Elmotaleb \& Saha, 2013).

Adanya kesulitan akademis terkadang membuat sebagian mahasiswa mengalami distress. Meskipun begitu, distress dapat dicegah dengan tingginya academic selfefficacy. Asumsi tersebut sejalan dengan temuan Kiamarsi dan Abolghasemi (2014) bahwa semakin tinggi self-efficacy semakin rendah kecenderungan mahasiswa mengalami distress. Berbagai kesulitan pun tidak membuat kondisi psikologis orang dengan academic self-efficacy yang tinggi, menjadi buruk.

Academic self-efficacy yang baik membuat mahasiswa menjalankan aktivitasnya secara optimal. Seseorang akan menilai bahwa dirinya mampu menjalankan rangkaian perilaku demi tercapainya target, menunjukkan bahwa dia optimis. Target akademis akan diraih dengan usaha yang tekun meskipun melalui berbagai tantangan, 
sehingga seorang mahasiswa perlu memiliki sifat pantang menyerah dan konsisten dengan target awalnya. Jika gagal dalam mencapai target, akan terus berusaha mencari ilmu agar menemukan solusi alternatif hingga tujuan awal tercapai. Individu dengan academic self-efficacy yang tinggi akan cenderung berusaha terus-menerus untuk mencapai target walaupun mengalami kesulitan (Komarraju \& Nadler (2013). Kesulitan yang dihadapi pun juga tidak direspon dengan keluhan hingga membuat kondisi psikologis memburuk, seperti yang diungkapkan dalam hasil penelitian Kiamarsi dan Abolghasemi (2014), bahwa self-efficacy berhubungan secara negatif dengan distress pada mahasiswa.

Karakteristik-karakteristik yang telah disebutkan sebelumnya, antara lain optimis, pantang menyerah walaupun mengalami masa sulit, konsisten dengan target awal, tidak mengeluh, dan punya semangat untuk mencari ilmu agar mendapatkan solusi pencapaian target, merupakan beberapa aspek dalam konstruk sabar. Konstruk sabar merupakan virtue atau nilai ideal yang berasal dari ajaran agama Islam. Definisi sabar adalah kemampuan memberi respon awal secara aktif dalam menahan emosi, pikiran, perkataan, dan perbuatan pada saat senang dan susah dengan mentaati aturan untuk tujuan kebaikan dengan didukung oleh optimisme, pantang menyerah, semangat mencari informasi atau ilmu untuk membuka solusi alternatif, konsisten, dan tidak mudah mengeluh (El Hafiz dkk, 2013).

Konstruk sabar memiliki beberapa komponen, yaitu aspek utama, aspek pendukung, dan atribut (El Hafiz dkk, 2013). Aspek utama yang meliputi respon awal berupa menahan, aktif memilih, taat aturan, tujuan kebaikan, saat senang dan susah. Lima aspek tersebut merupakan syarat mutlak yang harus dimiliki seseorang hingga dapat dikatakan sabar atau tidak. Hilangnya salah satu aspek menandakan individu tidak sabar. Aspek pendukung terdiri dari optimisme, pantang menyerah, semangat mencari informasi atau ilmu untuk membuka solusi alternatif, konsisten, dan tidak mudah mengeluh. Aspek-aspek tersebut yang ada pada individu menandakan tinggi atau rendahnya tingkat kesabaran. Hilangnya salah satu aspek pendukung tidak membuat seseorang dikatakan tidak sabar, namun tingkat kesabarannya lebih rendah daripada orang yang memiliki semua aspek. Atribut sabar adalah sesuatu yang berfungsi sebagai manifestasi proses kesabaran, yaitu emosi, pikiran, perkataan, dan perbuatan.

Kesabaran juga diperlukan oleh mahasiswa yang menjalani berbagai aktivitas akademisnya. Seorang mahasiswa perlu menahan dirinya dari perilaku mengeluh, putus asa, malas, atau hal-hal lain yang berpotensi menghambat pencapaian tujuannya yang baik, seperti target prestasi akademis. Kemampuan untuk bersabar memungkinkan dia terus berusaha walaupun menghadapi masa sulit karena tetap optimis, pantang menyerah, tetap konsisten berusaha mencapai target awal. Usaha pencapaian target juga dilakukan dengan mencari ilmu untuk mendapatkan solusi alternatif ketika mengalami kegagalan.

Telah dipaparkan sebelumnya bahwa terdapat beberapa kesamaan karakteristik kesabaran dan academic self-efficacy. Aspek optimis, pantang menyerah, konsisten, tidak mengeluh, dan semangat mencari ilmu 
untuk mendapatkan solusi, yang secara implisit terkandung dalam konstruk academic self-efficacy, juga merupakan aspek kesabaran. Dari penjelasan ini, peneliti terdorong untuk melakukan penelitian yang bertujuan untuk mencari tahu apakah ada hubungan antara kesabaran dan academic self-efficacy. Penelitian ini bermanfaat untuk elaborasi konstruk sabar sebagai konstruk psikologi yang baru. Usaha elaborasi ini dapat menjadi salah satu langkah untuk mengkonstruk teori kesabaran dan secara praktis dapat memberikan pemahaman yang komprehensif pada masyarakat mengenai makna sabar.

Optimisme dijelaskan dalam definisi self-efficacy menurut Bandura (1986), yaitu penilaian terhadap kemampuan diri sendiri dalam menjalankan rangkaian perilaku untuk mencapai suatu tujuan. Penilaian bahwa diri sendiri mampu berperilaku seperti yang ditargetkan menunjukkan sifat optimis. Aspek pantang menyerah dan konsisten dengan tujuan awal dijelaskan dalam temuan Komarraju dan Nadler (2013), bahwa mahasiswa dengan selfefficacy yang tinggi dapat berusaha secara terus-menerus untuk mencapai target walaupun menghadapi kesulitan. Usaha terus-menerus menunjukkan konsistensi dengan tujuan awal, sedangkan usaha yang terus dilakukan walaupun menghadapi kesulitan mengindikasikan sifat pantang menyerah. Jika menemui kesulitan hingga gagal, akan terdorong untuk terus mencari ilmu sebagai cara menemukan solusi mencapai tujuan awal. Aspek tidak mengeluh ditunjukkan dalam hasil penelitian Kiamarsi dan Abolghasemi (2014) bahwa semakin tinggi self-efficacy, semakin rendah kecen- derungan mahasiswa mengalami distress Situasi susah tidak dihadapi dengan keluhan, termasuk dalam pikiran atau emosinya sehingga mahasiswa dengan academic self-efficacy yang tinggi cenderung dapat terhindar dari distress.

Berdasarkan penjelasan tersebut, peneliti mengajukan hipotesis yaitu sebagai berikut

H1: Terdapat hubungan antara kesabaran academic self-efficacy

H2: Terdapat hubungan antara aspek optimis dan academic self-efficacy

H3: Terdapat hubungan antara aspek pantang menyerah dan academic self-efficacy

H4: Terdapat hubungan antara aspek konsisten dan academic selfefficacy

H5: Terdapat hubungan antara aspek tidak mengeluh dan academic selfefficacy

H6: Terdapat hubungan antara aspek semangat mencari ilmu dan academic self-efficacy

\section{METODE PENELITIAN}

\section{Subjek Penelitian}

Penelitian ini merupakan penelitian korelasional antara variabel kesabaran dan academic self-efficacy. Subjek adalah 108 mahasiswa di sebuah fakultas yang berstatus mahasiswa aktif yang berusia 18 sampai 22 tahun. Penentuan sampel dilakukan dengan cara convenience sampling.

\section{Metode Pengumpulan Data}

Instrumen penelitian berupa kuesioner yang terdiri dari tiga bagian. Bagian pertama dan kedua mengukur konstruk 
kesabaran, sedangkan bagian ke tiga mengukur konstruk academic self-efficacy. Alat ukur konstruk kesabaran disusun oleh El Hafiz et al. (2011), sedangkan konstruk academic self-efficacy diukur dengan versi adaptasi College Academic Self-efficacy Scale (CASES) yang disusun oleh Owen dan Froman (1988). Peneliti melakukan uji coba kedua alat ukur. Instrumen kesabaran memiliki nilai Cronbach Alpha sebesar 0.834, sedangkan CASES yang telah diadaptasi sebesar 0.889 sehingga dapat dikatakan bahwa kedua instrumen ukyr reliabel.

Prosedur penelitian dilakukan dengan cara meminta subjek untuk mengisi inisial nama, jenis kelamin, angkatan, dan bidang studi. Peneliti melakukan kontrol terhadap faktor jenis kelamin dan angkatan karena keduanya diduga dapat berpengaruh pada tingkat self-efficacy. Laki-laki dan perempuan dapat memiliki tingkat academic self-efficacy yang berbeda berdasarkan tugas yang dihadapi. Mahasiswa baru yang dalam penelitian ini adalah angkatan 2013, cenderung masih berada dalam masa adaptasi terhadap lingkungan akademis sehingga faktor angkatan dapat berpengaruh pada hasil penelitian. Pengambilan data dilakukan secara online melalui Google Drive dan secara manual. Setelah semua data Google Drive dan secara manual terkumpul, dilakukan skoring.

\section{Teknik Analisis Data}

Pengolahan data dilakukan dengan teknik korelasi Pearson Product Moment untuk uji hipotesis. Independent-samples $t$ test digunakan untuk mengontrol jenis kelamin terhadap academic self-efficacy, dan one-way ANOVA untuk mengontrol faktor angkatan.

\section{HASIL PENELITIAN}

Berikut adalah tabel yang berisi jumlah subjek penelitian berdasarkan jenis kelamin dan angkatan.

Tabel 1. Frekuensi Subjek berdasarkan Jenis Kelamin

\begin{tabular}{cc}
\hline Jenis Kelamin & N \\
\hline Laki-laki & 22 \\
Perempuan & 86 \\
\hline Total & 106 \\
\hline
\end{tabular}

Tabel 2. Frekuensi Subjek berdasarkan Angkatan

\begin{tabular}{cc}
\hline Angkatan & $\mathrm{N}$ \\
\hline 2011 & 36 \\
2012 & 32 \\
2013 & 40 \\
\hline Total & 106 \\
\hline
\end{tabular}

Data dalam Tabel 1 menunjukkan bahwa sebagian besar subjek adalah perempuan dengan jumlah 86 orang. Jumlah subjek laki-laki sekitar seperempat dari 
jumlah subjek perempuan, yaitu 22 orang. Berdasarkan Tabel 2, jumlah terbanyak subjek ada pada angkatan 2013, yaitu 40 orang. Jumlah terbanyak kedua adalah kelompok angkatan 2011 yang berjumlah 36 orang, kemudian diikuti oleh angkatan 2013 sebanyak 32 orang.

Hasil penelitian adalah sebagai berikut.

Tabel 3. Korelasi antara Kesabaran dan Academic Self-efficacy

\begin{tabular}{lcc}
\hline & \multicolumn{2}{c}{ Academic self-efficacy } \\
\cline { 2 - 3 } & $\mathrm{r}$ & $\mathrm{r}^{2}$ \\
\hline Kesabaran & $0.320^{* *}$ & 0.103 \\
\hline Signifikan pada $\mathrm{p}<0.01$ (1-tailed)
\end{tabular}

Berdasarkan Tabel 3, terlihat bahwa nilai korelasi antara variabel kesabaran dan academic self-efficacy sebesar $\mathrm{r}=0.320, \mathrm{p}<$ 0.01 (1-tailed). Hasil ini menunjukkan hipotesis pertama terbukti benar. Terlihat juga bahwa nilai koefisien determinasi sebesar $\mathrm{r}^{2}=0.103$ yang artinya academic self-efficacy berkontribusi sebanyak $10.3 \%$ terhadap kesabaran.

Tabel 4. Korelasi antara Aspek Kesabaran dan Academic Self-efficacy

\begin{tabular}{cc}
\hline Kesabaran & \multicolumn{2}{c}{ Academic self-efficacy } \\
\cline { 2 - 2 } & $\mathrm{R}$ \\
\hline Optimis & $0.333^{* *}$ \\
Pantang menyerah & $0.210^{*}$ \\
Konsisten & $0.198^{*}$ \\
Tidak mengeluh & 0.34 \\
Semangat mencari ilmu & $0.294^{* *}$ \\
* Signifikan pada $\mathrm{p}<0.05$ (2-tailed) & \\
** Signifikan pada $\mathrm{p}<0.01$ (1-tailed) &
\end{tabular}

Tabel 3 dan 4 menunjukkan nilai korelasi antara aspek pendukung dalam kesabaran dan academic self-efficacy. Aspek optimis dan academic self-efficacy berkorelasi sebesar $r=0.333, \mathrm{p}<0.01$ (1-tailed) sehingga mendukung hipotesis 2. Korelasi antara aspek pantang menyerah dan academic self-efficacy sebesar $r=0.210$, $p<$ 0.05 (2-tailed), membuktikan hipotesis 3 benar. Aspek konsisten memiliki korelasi sebesar $r=0.198, p<0.05$ (2-tailed) dengan academic self-efficacy, menunjukkan bahwa hipotesis 4 terbukti benar. Hasil uji hipotesis 5, yaitu korelasi antara aspek tidak mengeluh dan academic self-efficacy, tidak terbukti signifikan. Hubungan antara aspek semangat mencari ilmu dan academic selfefficacy adalah $\mathrm{r}=0.294, \mathrm{p}<0.01$ (1-tailed), menunjukkan hipotesis 6 terbukti benar. 


\section{PEMBAHASAN}

Hasil penelitian yang diperoleh berdasarkan korelasi Pearson mengungkapkan bahwa terdapat hubungan signifikan antara kesabaran dan academic self-efficac. Korelasi yang dihasilkan sangat kecil, yaitu $\mathrm{r}$ $=0.320$. Koefisien determinasi adalah $\mathrm{r}^{\mathrm{r}}=$ $10.3 \%$, artinya sebanyak $10.3 \%$ variabilitas skor kesabaran diprediksi oleh hubungannya dengan skor academic self-efficacy. Selebihnya, yaitu sebanyak 89,7\% merupakan error. Jumlah error yang besar tersebut dapat disebabkan oleh faktor-faktor yang tidak diukur namun sebenarnya mempengaruhi hubungan antara kesabaran dan academic self-efficacy.

Peneliti juga mengontrol faktor jenis kelamin dan angkatan yang diduga mempengaruhi korelasi antara dua variabel utama. Berdasarkan analisis statistik independentsamples t-test, diperoleh bahwa tidak ada perbedaan signifikan antara laki-laki dan perempuan dalam academic self-efficacy. Hasil ini mendukung temuan Williams dan Takaku (2011) yang mengungkapkan bahwa tidak ada perbedaan antara laki-laki dan perempuan dalam writing self-efficacy. Diperoleh hasil yang serupa juga ketika mengontrol faktor angkatan, yaitu tidak ada perbedaan signifikan antar angkatan dalam academic self-efficacy. Dengan demikian, jenis kelamin dan angkatan cenderung tidak berpengaruh terhadap hubungan antara dua variabel utama.

Telah ditemukan juga hasil yang lebih rinci dalam melihat hubungan antara kesabaran academic self-efficacy. Dengan mengelaborasi kesabaran menjadi beberapa aspek, ditemukan bahwa aspek optimis, pantang menyerah, konsisten, dan semangat mencari ilmu, berkorelasi secara positif dengan academic self-efficacy. Hasil korelasi tersebut dapat dijelaskan oleh pernyataan Bandura (1986) mengenai definisi selfefficacy yang mengandung aspek optimis, dan Komarraju serta Nadler (2013), bahwa mahasiswa dengan self-efficacy yang tinggi berusaha secara terus-menerus untuk mencapai target walaupun menghadapi kesulitan. Berbeda dengan tiga aspek tersebut, aspek tidak mengeluh tidak berhubungan dengan academic self-efficacy. Temuan ini tidak sesuai dengan yang diungkapkan Kiamarsi dan Abolghasemi (2014), bahwa self-efficacy berhubungan secara negatif dengan distress pada mahasiswa.

Terdapat beberapa keterbatasan dalam penelitian ini. Pertama, jumlah sampel yang kecil sehingga hasil penelitian masih kurang menggambarkan kondisi populasi. Kedua, kecilnya nilai koefisien determinasi yaitu sebesar $10.3 \%$ menunjukkan faktor error masih sangat besar. Berarti ada faktor-faktor lain yang mempengaruhi korelasi namun tidak dijadikan variabel yang diteliti. Ketiga, kontrol penelitian kurang ketat. Peneliti hanya mengontrol faktor jenis kelamin dan angkatan, namun keduanya tidak berpengaruh pada dua variabel utama sementara faktor error penelitian ini sangat besar. Penyebab yang mungkin melatarbelakangi ini adalah jumlah sampel yang sedikit. 


\section{PENUTUP}

\section{Simpulan}

Kesimpulan yang diperoleh berdasarkan hasil penelitian adalah terdapat hubungan antara kesabaran dan academic selfefficac. Semakin tinggi academic self-efficacy, cenderung semakin tinggi juga tingkat kesabaran. Aspek kesabaran pendukung dalam kesabaran yang berhubungan dengan academic self-efficacy adalah optimis, pantang menyerah, konsisten, dan semangat mencari ilmu. Artinya, orang dengan academic self-efficacy yang tinggi cenderung memiliki sifat optimis, pantang menyerah, konsisten dengan tujuan awal, dan semangat mencari ilmu untuk mendapatkan solusi alternatif.

\section{Saran}

Peneliti memberikan beberapa saran untuk perbaikan studi ini dan sekaligus dapat menjadi rekomendasi bagi penelitian lanjutan dengan topik serupa. Pertama, perlu adanya studi dengan sampel yang lebih banyak agar hasil penelitian dapat lebih merepresentasikan kondisi populasi. Kedua, mengenai konstruk academic selfefficacy. Konstruk ini dapat diteliti dalam berbagai konteks lain, mengingat selfefficacy bersifat spesifik terhadap suatu bidang dan belum tentu sama dalam bidang lain. Ketiga, mengenai sabar sebagai konstruk baru. Perlu ada penelitianpenelitian lanjutan mengenai kesabaran sebagai usaha eksplorasi dan elaborasi hingga pada akhirnya menjadi sebuah teori. Penelitian lanjutan dapat dilakukan dalam konteks lain di mana individu mungkin menghadapi situasi sulit, seperti keluarga, pemerintahan, pekerjaan, organisasi, kelompok sosial dalam masyarakat luas, dan sebagainya. Sabar juga merupakan virtue atau nilai ideal yang perlu dicapai. Sejauh ini belum ada studi mengenai seberapa sabar orang-orang Indonesia. Penelitian deskriptif dalam skala besar dapat dilakukan untuk mengetahui kesabaran pada masyarakat sehingga dapat terlihat sejauh mana kebanyakan orang, terutama Muslim, menjalani salah satu ajaran Islam. Berbagai hasil penelitian mengenai kesabaran dapat dijadikan dasar untuk melakukan intervensi psikologis dengan melibatkan sabar sebagai virtue yang akan diinternalisasi. Dengan demikian, akan semakin banyak orang yang memahami konsep sabar dengan lebih komprehensif.

\section{DAFTAR PUSTAKA}

Abd-Elmotaleb, M. \& Saha, S. K. (2013). The role of academic self-efficacy as a mediator variable between perceived academic climate and academic performance. Journal of Education and Learning, 2 (3)

Bandura, A. (1986). Social foundations of thought and action: a social cognitive theory. New Jersey: Prentice-Hall, Inc.

El Hafiz. S, Rozi. F, Lila.P, Mundzir. I. (2013). Sabar (patience) as new psychological construct. Dipresentasikan dalam 10th Biennal Conference of Asian Association of Social Psychology, Yogyakarta. 
Feldman, D. B., \& Kubota, M. (2015). Hope, self-efficacy, optimism, and academic achievement: distinguishing constructs and levels of specificity in predicting college grade-point average. Learning and Individual Differences, 37, 210216.

Kiamarsi, A., \& Abolghasemi, A. (2014). The relationship of procrastination and self-efficacy with Psychological vulnerability in students. Social and Behavioral Sciences, 114,858-862.

Klassen, R. M., Krawchuk, L. L., Rajani, S. (2008). Academic procrastination of undergraduates: Low self-efficacy to self-regulate predicts higher levels of procrastination. Contemporary Educational Psychology, 33, 915-931.

Komarraju, M., \& Nadler, D. (2013). Selfefficacy and academic achievement: why do implicit beliefs, goals, and effort regulation matter? Learning and Individual Differences, 25, 67- 72.

Li, L. K. Y. (2012). A study of the attitude, self-efficacy, effort and academic achievement of CityU students towards research methods and statistics. Discovery - SS Student EJournal, 1, 154-183. Diunduh pada 15 Februari
2015, dari http://ssweb.cityu.edu.hk/ download/RS/E-Journal/journal8.pdf

Lindstrøm, C., \& Sharma, M. D. (2011). Selfefficacy of first year university physics students: do gender and prior formal instruction in physics matter ?. International Journal of Innovation in Science and Mathematics Education, 19 (2). 1-19. Diunduh pada 19 Februari 2015, dari http://openjournals. library.usyd.edu.au/index.php/CAL/a rticle/download/4770/5767

Owen, S V., \& Froman, S. D. (1988). Development of a College Academic Self-efficacy Scale. Paper Dipresentasikan dalam Annual Meeting of the National Council on Measurement in Education, New Orleans.

Williams, J. D., \& Takaku, S. (2011). Gender, writing self-efficacy, and help seeking. International Journal of Business, Humanities and Technology, 1 (3). Diunduh pada 19 Februari 2015, dari http://www.ijbhtnet.com/journals/V ol_1_No_3_November_2011/5.pdf

Zimmerman, B. J. (2000). Self-efficacy: an essential motive to learn. Contemporary Educational Psychology, 25, 82-91. 